\title{
Performance Analysis and Improvement of OFDM System Based on BCH Channel Coding and DCT Technique
}

\author{
Ali Jawad Tbada and Muntadher Kadhim Abdullah \\ Department of Computer Technical Engineering, College of Technical Engineering, \\ The Islamic University, Najaf, Iraq
}

\begin{abstract}
Principles of Orthogonal Frequency Division Multiplexing (OFDM) are widely used in wireless communication. In OFDM system, many digital data are transmitted as sub-carriers. All sub-carriers are orthogonal to each other. High spectral efficiency are obtained due to the spectrum are quite narrow. OFDM also has advantages of saving of bandwidth, easy to implement modulation and demodulation, easy equalization, protection against Inter-Symbol Interference (ISI) and so on. However with all these advantages, there is a major disadvantage that it has large Peak-to-Average Power Ratio (PAPR). Large PAPR value makes system performance quite sensitive to distortion introduced by nonlinear amplifier, caused by nonlinear components. These non-linear components make the Bit Error Rate (BER) performance degraded. In this study, a proposed OFDM system based on $\mathrm{BCH}$ channel coding and Discrete Cosine Transform (DCT) technique are used to enhance performance of OFDM system by reducing the PAPR value without serious increasing in computational complexity and this leads to reduce the BER. BER performance also will be improved over Additive White Gaussian Noise (AWGN) and fading channels. All these are obtained with low cost of implementation, simple hardware and no require side information. Finally, results of simulation show the proposed system performance are much better comparing with that of the conventional OFDM system.
\end{abstract}

Key words: OFDM, DCT, PAPR, ISI, BCH, hardware

\section{INTRODUCTION}

The definition of frequency-selective channel is either the symbol period $\mathrm{T}$ is lower than the maximum delay of the channel's impulse response $\mathrm{T}_{\mathrm{m}}$ or the channel's bandwidth $\mathrm{B}$ is large than the coherence band $B_{C}$. The receiver will be exposed to ISI when the channel is frequency-selective. To reduce ISI, equalizer must be used in the receiver. It is difficult to build an equalizer practically. To avoid channel equalization, each channel separated to several sub-bands, so that, $\mathrm{B} \leq 0.1 \mathrm{BC}$. Thus, ISI will be eliminated in each sub-band. This is the principle of multi-carrier communication system (Pischella and Ruyet, 2015). There are several multi-carrier modulations exist, one of these types is OFDM. In broadband wireless communication, OFDM are vastly used. Multi sub-carriers are used to send data. The sub-carriers are orthogonal one to another. High spectral efficiency is obtained because of orthogonality (Patidar and Parikh, 2011). OFDM also has advantages of saving of bandwidth, easy to implement modulation and demodulation, easy equalization, protection against ISI

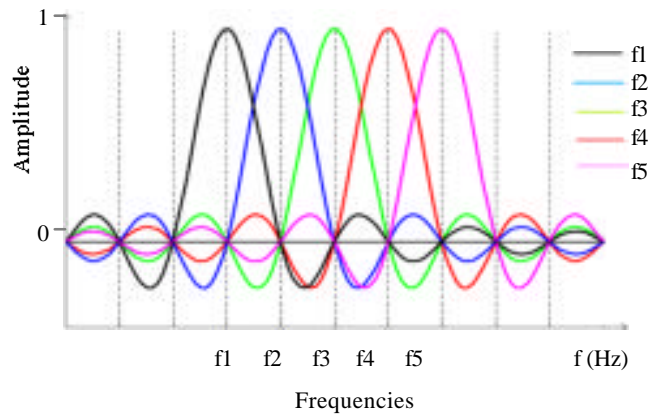

Fig. 1: Spectrum of OFDM signal

and so on. The orthogonality property is shown in Fig. 1. Inverse Discrete Fourier Transform (IDFT) is used to get modulation process also the demodulation process is achieved by using Discrete Fourier Transform (DFT) (Edfors et al., 1995). There is a problem with using these transforms, the problem is very large number of complex multiplications.

To solve this problem, Fast Fourier Transform (FFT) is used to reduce the number of complex multiplications (Minallah and Raja, 2006).

Corresponding Author: Ali Jawad Ibada, Department of Computer Technical Engineering, College of Technical Engineering, The Islamic University, Najaf, Iraq 


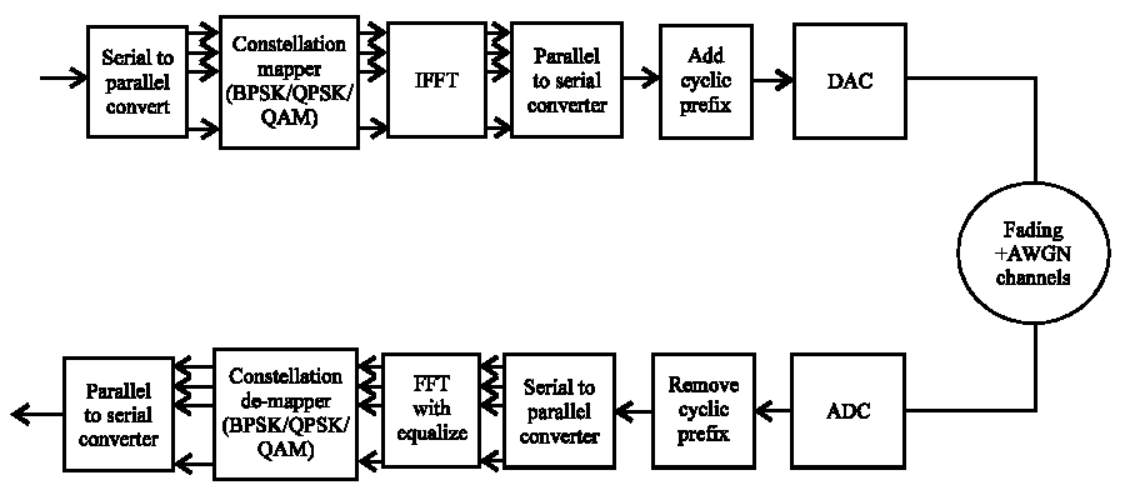

Fig. 2: Conventional OFDM transceiver system

Unfortunately with all advantages of OFDM, there is a major disadvantage. It has large PAPR value. Large PAPR value occurs when all subcarriers are added. Thus, the peak power is $\mathrm{N}$ times higher than the average power. Large PAPR value leads to degrade the performance of OFDM system by making the analog amplifier operates in the nonlinear range. This degrades the BER performance because the signal will be distorted also the amplifier will consume extra power (Natalia and Mathar, 2008). Many previous researchers had studied PAPR reduction techniques (Albdran et al., 2012; Pradeep et al., 2013; Jayashri et al., 2015; Chih-Peng et al., 2010; Alekya and Mohana, 2016; Koudougnon et al., 2012; Gupta and Saxena, 2013; Gupta and Bhadauria, 2013; Garg et al., 2017) including clipping, coding, companding transform, Partial Transmit Sequence (PTS), Selective Mapping (SLM) and so on. However, most of these proposed schemes have either low BER performance or a high complex mathematical operations as well as higher hardware complexity of transmitter and receiver. This research is proposed a method based on $\mathrm{BCH}$ channel coding and DCT technique. MATLAB Software is used to build the proposed system and the simulation results show clearly the reduction in the PAPR value which leading to reduce BER. The BER is improved also over AWGN and multipath channels.

OFDM system model: The traditional OFDM transceiver block diagram is shown in Fig. 2. In a chain of transmission, generate a binary data series representing the voice, data, image or analog information. At the beginning, the serial binary data will convert to parallel stream according to number of sub-carriers $(\mathrm{N})$. The individual parallel data streams are modulated into digital modulation format (QAM, QPSK, BPSK, etc.). At this point, constellation mapper is achieved. Then, orthogonal subcarriers are required for transmission (Viswanathan, 2013). IDFT is used to get these orthogonal subcarriers. Same operation can be performed by Inverse Fast Fourier
Transform (IFFT) but IFFT requires less multiplication hardware. Equation 1 and 2 for FFT/IFFT function are shown below:

$$
\begin{aligned}
& Y(k)=\sum_{n=0}^{N-1} y(n) e^{-\frac{j 2 \pi k n}{N}} \\
& y(n)=\sum_{k=0}^{N-1} Y(k) e^{+\frac{j 2 \pi k n}{N}}
\end{aligned}
$$

Where:

$y(n)=$ The discrete time domain of OFDM signal

$\mathrm{Y}(\mathrm{k})=$ The frequency domain

Equation 1 is used to calculatethe FFT and Eq. 2 for IFFT. The OFDM time domain signal is carried by the required frequency (Gupta and Bhadauria, 2013).

The final part of the samples is copied to the beginning of OFDM signal before transmission, this operation called Cyclic Prefix (CP). CP is used to reduce ISI. At receiver part, all these process are reversed to get back information. CP is discarded before FFT is applied. After the FFT is performed, a simple equalizer is used to estimate the transmitted OFDM symbols. Finally, bit stream recovered by decoding the complex symbols (Sajedin et al., 2014).

Peak to Average Power Ratio (PAPR): PAPR in OFDM signal is defined as a ratio of the instant peak power of the signal to mean power as shown in Eq. 3:

$$
\operatorname{PAPR}=\frac{\max \left[\mathrm{y}(\mathrm{n})^{2}\right]}{\mathrm{E}\left\{|\mathrm{y}(\mathrm{n})|^{2}\right\}}
$$

Where:

$\max [y(n)]^{2}=$ The instant peak power of $y(n)$

$\mathrm{E}\left\{|\mathrm{y}(\mathrm{n})|^{2}\right\}=$ The average power of $\mathrm{y}(\mathrm{n})$ (Choudhary and Gupta, 2013)

The large PAPR value in OFDM system is the main disadvantage because of it produces distortion in signal 
and poor efficiency of power (Joshi, 2012). The reason of large PAPR is the large dynamic range of input signal. To design any system has to research with large dynamic range of the signal, alarge linear region is required. To deal with large PAPR, it requires highly efficient High Power Amplifier (HPA) that work in large linear region. Because of large linear region, the components of HPA are failed to build, thus, result in saturation (Khalid, 2009; Cho et al., 2010). The saturation produces in band distortion which increasing BER and out of band which causes Adjacent Channel Interference (ACI). Therefore, it is important to reduce PAPR value before transmitting the signal into nonlinear Digital to Analog Converter (DAC) and HPA to improve both BER vs. $E_{0} / N$ 。 performance of the system and the power efficiency (Khalid, 2009; Cho et al., 2010).

\section{MATERIALS AND METHODS}

Proposed OFDM system: The proposed OFDM System is shown in Fig. 3. This system consists of two extra components compared with conventional OFDM system. The first component is adding channel coding to the system and the second component is adding the Discrete Cosine Transforms (DCT) before IFFT block in the transmitter and adding Inverse DCT (IDCT) after FFT block in the receiver.

Channel coding: In practical, no transmitted signal can reach its destination without affected by noise. To make the transmitted signals to better combat of different channel deterioration, therefore a channel coding is used (Sklar, 2001). The process of channel coding is putting additional bits (called parity check or correction bits) to data before transmission that makes the receiver find out or correct errors in capable limitations. The classification of channel codes are: convolutional codes and block codes. A separate mathematical structure is used in convolutional codes. On the other hand, block codes are used abstract algebra and arithmetical finite field. The $\mathrm{k}$ information block bits are converted to $\mathrm{n}$ block coded bits which produce $(\mathrm{n}, \mathrm{k})$ block codes. Examples of block codes are Bose Chaudhuri Hocquenghem $(\mathrm{BCH})$ codes and hamming codes (Sklar, 2001).

However, in this research the $\mathrm{BCH}$ codes are chosen as a channel coding method. The block length in $\mathrm{BCH}$ is unlimited with different code rates. Class of $\mathrm{BCH}$ codes is a large class of cyclic multiple error correcting codes. Binary $\mathrm{BCH}$ code has the parameters: $\mathrm{n}=2^{\mathrm{m}}-1, \mathrm{n}-\mathrm{k}=$ $r \leq m t$, minimum Hamming Distance $H D \geq 2 t+1$ for $m \geq 3$ and $\mathrm{t}<2^{\mathrm{m}-1}$ where $\mathrm{r}$ is parity check or correction bits, $\mathrm{t}$ is the number of error correcting capability and $\mathrm{m}$ is integer positive number. So, $\mathrm{n}$ takes only the values $7,15,31,63$, ..., these values are the dimension of the non zero elements of Galois Felds (GF) ( $2^{\mathrm{m}}$ ) (Sklar, 2001).

The decoding algorithm of $\mathrm{BCH}$ is simple and easily realized that is capable of correcting all random patterns of $t$ errors.

BCH code generation: The parity check matrix $[\mathrm{H}]$ of this $\mathrm{BCH}$ code with $\mathrm{n}=2^{\mathrm{m}}-1$ can be written in terms of the primitive non-zero elements of GF $\left(2^{\mathrm{m}}\right)$. The general form of it is Eq. 4:

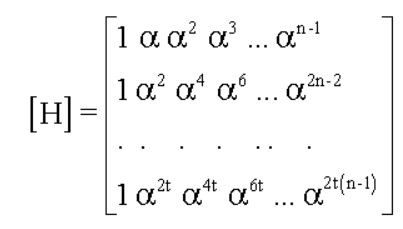

where, $\mathrm{a}$ is a primitive non-zero element in $\mathrm{GF}\left(2^{\mathrm{m}}\right)$. Notice that it is written such that the elements of the 2nd row are the squares of the 1 st row and the elements of the 3rd row are the cubic of the elements of the 1 st row and so on. Also, the number of rows is twice the error correction capability (2t). The generator polynomial $\mathrm{g}(\mathrm{x})$ will Eq. 5:

$$
g(x)=\operatorname{LCM}\left\{M^{1}(x) M^{2}(x) M^{3}(x), \ldots, M^{2 t}(x)\right\}
$$

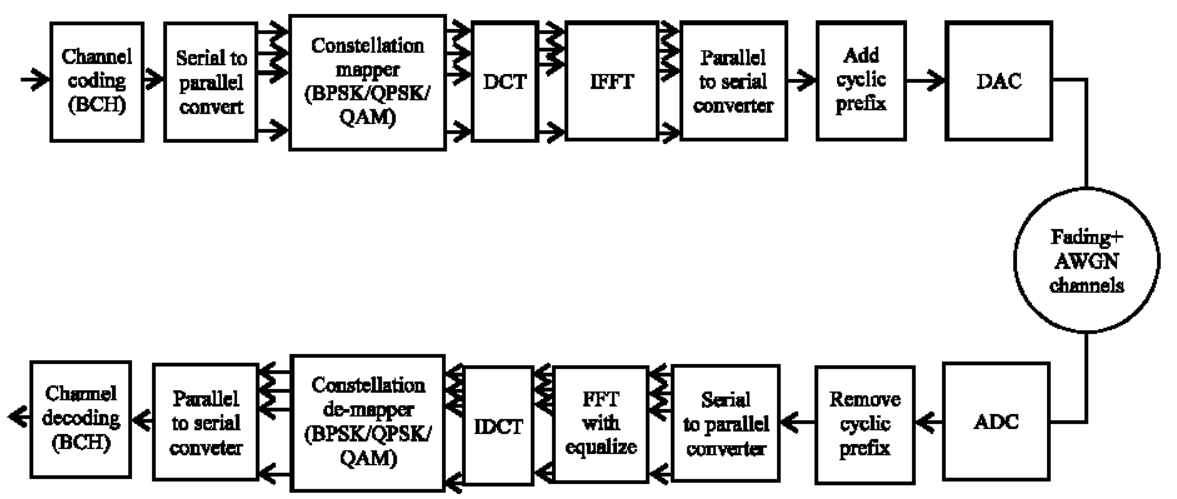

Fig. 3: Proposed OFDM system 
Where:

LCM $=$ The Least Common Multiple

$\mathrm{M}^{\mathrm{i}}(\mathrm{x})=$ The Minimal polynomial for the non-zero elements a $a^{i}$ for $i=1,2, \ldots, 2 t$ (Khalid, 2009)

A systematic (n, k) cyclic code word is generated from a generator polynomial $g(x)$ of order $r$ such that if Data (D) $=\left[\mathrm{d}_{1}, \mathrm{~d}_{2}, \ldots, \mathrm{d}_{\mathrm{k}}\right]$, then, $\mathrm{d}(\mathrm{x})$ is the data polynomial Eq. 6:

$$
d(x)=d_{k}+d_{k-1} x+, \ldots,+d_{2} x^{k-2}+d_{1} x^{k-1}
$$

Whereas are the data digits, then, the codeword output will be Eq. 7:

$$
C(x)=\operatorname{Rem} \frac{x^{r} \cdot d(x)}{g(x)}+x^{r} d(x)
$$

where, Rem is the Remainder of long division.

Binary BCH codes: For binary BCH coding, then, it can show that the minimal polynomials for every even power of a is the same as some previous odd power, then Eq. 8:

$$
g(x)=\operatorname{LCM}\left\{M^{1}(x) M^{3}(x) M^{5}(x), \ldots, M^{2 t-1}(x)\right\}
$$

And parity check matrix used for code generation is Eq. 9:

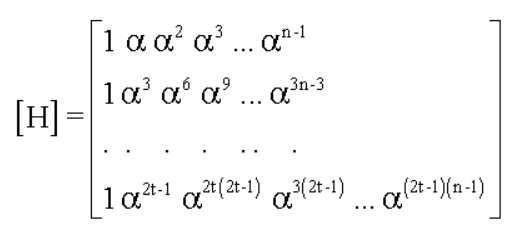

Decoding of BCH codes: Suppose that transmitted polynomial is Eq. 10:

$$
\mathrm{C}(\mathrm{x})=\mathrm{c}_{0}+\mathrm{c}_{1} \mathrm{x}+\mathrm{c}_{2} \mathrm{x}^{2}+\ldots,+\mathrm{c}_{\mathrm{n}-1} \mathrm{x}^{\mathrm{n}-1}
$$

If the received polynomial is Eq. 11:

$$
\mathrm{R}(\mathrm{x})=\mathrm{r}_{0}+\mathrm{r}_{1} \mathrm{x}+\mathrm{r}_{2} \mathrm{x}^{2}+\ldots,+\mathrm{r}_{\mathrm{n}-1} \mathrm{x}^{\mathrm{n}-1}
$$

Let $\mathrm{E}(\mathrm{x})$ be error polynomial, then $\mathrm{R}(\mathrm{x})=\mathrm{C}(\mathrm{x})+\mathrm{E}(\mathrm{x})$. To decode $\mathrm{BCH}$ codes efficiently, it must be firstly calculate the syndromes elements in $\mathrm{GF}\left(2^{\mathrm{m}}\right)[\mathrm{S}]=\left[\mathrm{S}_{1} \mathrm{~S}_{2} \mathrm{~S}_{3}\right.$ $\mathrm{S}_{2 t}$ ] by multiplying the received codeword [R] with [H], secondly find the error location polynomial from [S] and finally determine the locations of errorsby finding the roots of the error location polynomial (Ryan and Lin, 2009).
DCT: It is a one type of fourier transformation family such as DFT. The calculation of DCT is fast, real, separable and orthogonal. Its transformed data has better energy and compression. Compare to DFT, DCT has lower energy, less complexity, real symmetric transformation (Gupta and Saxena, 2013). One dimensional-DCT Z [k] is given Eq. 12:

$$
\mathrm{Z}(\mathrm{k})=\sum_{\mathrm{n}=0}^{\mathrm{N}-1} \mathrm{Z}(\mathrm{n}) \cos \left(\frac{2 \pi \mathrm{nk}}{\mathrm{N}}\right)
$$

where, $\mathrm{k}=0,1,2,3, \ldots, \mathrm{N}-1$. And one dimensional inverse discrete cosine transform (1D-IDCT) $\mathrm{x}(\mathrm{k})$ is given (Jagadeesh, 2007) (Eq. 13):

$$
\mathrm{Z}(\mathrm{n})=\sum_{\mathrm{k}=0}^{\mathrm{N}-1} \mathrm{Z}(\mathrm{k}) \cos \left(\frac{2 \pi \mathrm{nk}}{\mathrm{N}}\right)
$$

Where $\mathrm{n}=0,1,2,3, \ldots, \mathrm{N}-1$. Discrete-time sinusoids are given Eq. 14:

$$
\mathrm{C}(\mathrm{N}, \mathrm{K})=\cos \left(\frac{2 \pi \mathrm{nk}}{\mathrm{N}}\right)
$$

where, $\mathrm{n}=0,1,2,3, \ldots, \mathrm{N}-1, \mathrm{k}=0,1,2,3, \ldots, \mathrm{N}-1$. DCT matrix $\mathrm{C}(\mathrm{n}, \mathrm{k})$ are orthogonal matrix vectors (Rows or Columns), this is used to decrease autocorrelation between the OFDM signals. Thus, less PAPR is obtained (Hsu and Do, 2007). So that, the relationship between PAPR and autocorrelation is given below Eq. 15:

$$
\operatorname{PAPR}=1+\frac{2}{\mathrm{~N}} \sum_{\mathrm{k}=0}^{\mathrm{N}-1}|\mathrm{p}|
$$

where, $\mathrm{p}$ is the autocorrelation of the OFDM signal.

\section{RESULTS AND DISCUSSION}

Studying performance of the proposed OFDM system is performed using MATLAB program. Table 1 shows simulated parameters that were used in OFDM system as defined in IEEE 802.11 specifications. Firstly, the simulation result of PAPR when using the conventional OFDM system is shown in Fig. 4.

PAPR is large value, so that, it equals to $16 \mathrm{~dB}$. Remind that a larger PAPR value makes system complex, increasing BER and the efficiency of power amplifier is decrease. When placing DCT technique before FFT in the system, PAPR approximately equals to $4.94 \mathrm{~dB}$ as shown in Fig. 5. PAPR here has an advantage over conventional OFDM, it has lower value because of DCT reduces the autocorrelation between the OFDM signals which is one of root cause to PAPR reduction. 


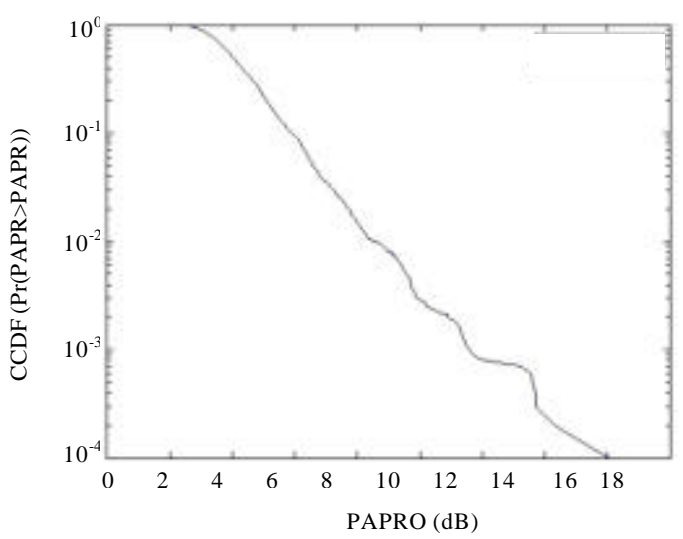

Fig. 4: PAPR value when using the conventional OFDM system (original)

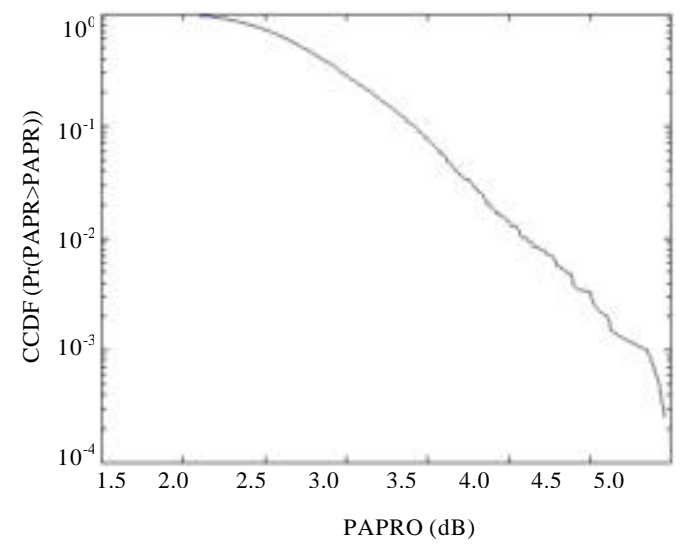

Fig. 5: PAPR value of OFDM system when using DCT technique

Table 1: OFDM system simulated parameters

\begin{tabular}{ll}
\hline Simulated parameters & Values \\
\hline System bandwidth & $20 \mathrm{MHz}$ \\
Used data subcarriers $=\mathrm{N}_{\mathrm{sd}}$ & $35 \mathrm{bits}$ \\
Pilot subcarriers $=\mathrm{N}_{\mathrm{sp}}$ & 4 bits \\
Total used subcarriers & $\mathrm{N}_{\mathrm{st}}=\mathrm{N}_{\mathrm{sp}}+\mathrm{N}_{\mathrm{sp}}=39 \mathrm{bits}$ \\
Unused data subcarriers $=\mathrm{N}_{\text {unused }}$ & 1 bit \\
Bits after channel coding, & $\mathrm{n}=\mathrm{N}_{\mathrm{st}}+$ redundant bits $\mathrm{n}=63$ \\
channel codeword & bits \\
Channel coding & $\mathrm{BCH}$ code $(39,63)$ \\
Total subcarriers or $\mathrm{N}_{\mathrm{FFT}}$ (FFT length) & $\mathrm{N}_{\mathrm{FFT}}=\mathrm{n}+\mathrm{N}_{\text {urused }}=64 \mathrm{bits}$ \\
BW of each subcarrier & $\Delta \mathrm{F}=\mathrm{BW}$ of the system $/ \mathrm{N}_{\mathrm{FFT}}$ \\
& $=20 \mathrm{MHz} / 64=312500 \mathrm{~Hz}$ \\
$\mathrm{~T}_{\mathrm{FFT}}=1 / \Delta \mathrm{F}$ (FFT or IFFT period) & $3.2 \eta \mathrm{sec}$ \\
$\mathrm{T}_{\mathrm{cp}}$ (duration time of CP) & $\mathrm{T}_{\mathrm{cp}}=\mathrm{T}_{\mathrm{FFF}} / 4=0.8 \mu \mathrm{sec}$ \\
Total duration of BPSK-OFDM symbol & $\mathrm{T}_{\mathrm{OFDM}}=\mathrm{Tcp}+\mathrm{T}_{\mathrm{FFT}}=4 \mu \mathrm{sec}$ \\
Bits allocated to CP & $\mathrm{N}_{\mathrm{cp}}=\mathrm{N} * \mathrm{~T}_{\mathrm{Cp}} / \mathrm{T}_{\mathrm{FFT}}=16 \mathrm{bits}$ \\
Error correction capability (t) & 4 bit errors are corrected in each \\
& OFDM symbol \\
OFDM symbols that are transmitted & 5000 OFDM symbols \\
\hline
\end{tabular}

The proposed OFDM system in this research uses both DCT and $\mathrm{BCH}$ channel coding. DCT used here to reduce $\mathrm{PAPR}$ while $\mathrm{BCH}$ used for detecting and correcting

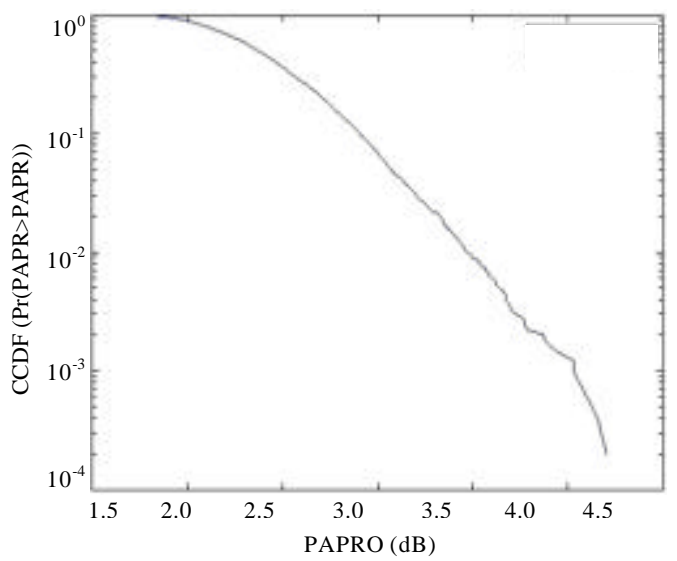

Fig. 6: PAPR value when using the proposed OFDM system (original)

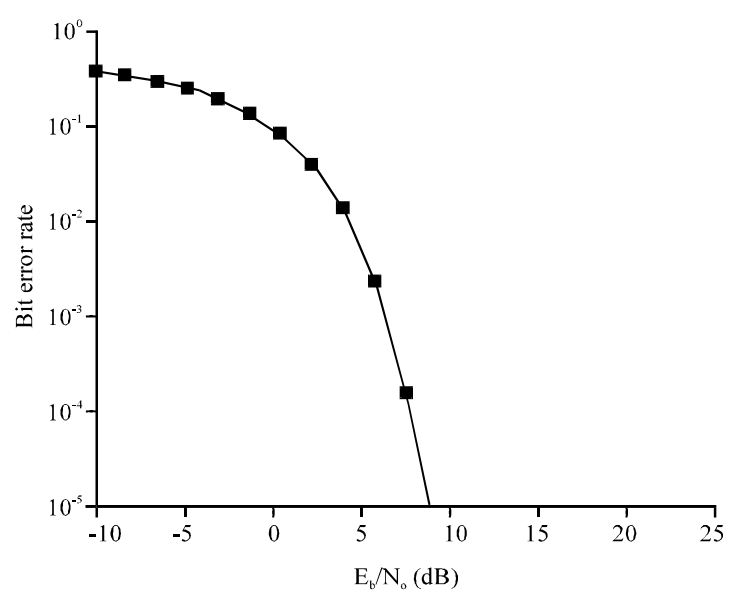

Fig. 7: BER vs. $\mathrm{E}_{\mathrm{b}} / \mathrm{N}_{0}$ performance when using the conv. OFDM system over AWGN channel

errors as well as reducing PAPR because of the redundant bits. Therefore, PAPR when using the proposed OFDM system is shown in Fig. 6. PAPR here equals to $4.233 \mathrm{~dB}$ which reduced by $11.767 \mathrm{~dB}$ in compared with conventional OFDM system while it is reduced by $0.707 \mathrm{~dB}$ in compared with using DCT only.

This proposed method is compared with another research which used Selective Mapping (SLM) method in (Mhatre and Khot, 2015). In this research, PAPR is approximately $4.233 \mathrm{~dB}$ while PAPR in SLM method is $6.391 \mathrm{~dB}$ at $\mathrm{U}=16$ (number of phase sequences) and $\mathrm{PAPR}=7.1 \mathrm{~dB}$ at $\mathrm{U}=8$. Also in this study, the reduction of PAPR value is obtained without serious increasing in computational complexity as well as low hardware complexity.

Now, the system performance widely improved after reducing the PAPR value. But AWGN and fading channels also degrade the performance of OFDM system 


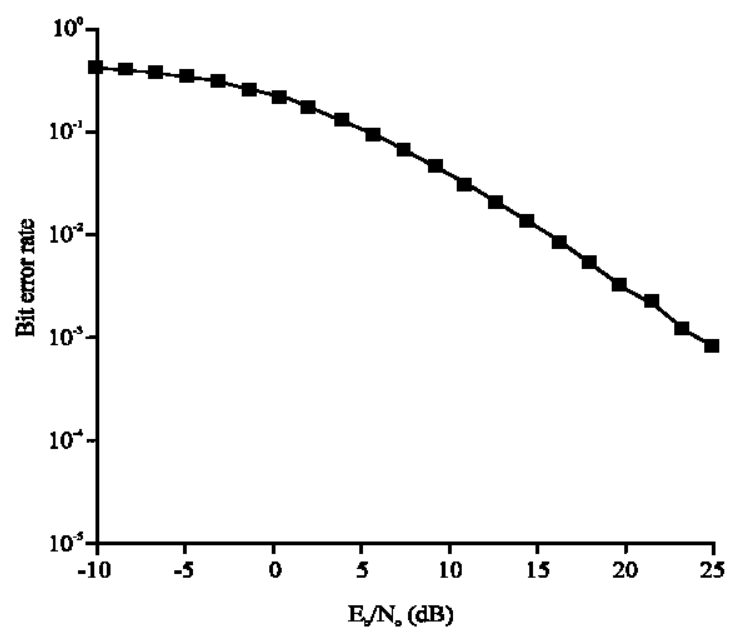

Fig. 8: BER vs. $\mathrm{E}_{\mathrm{b}} / \mathrm{N}_{0}$ performance when using the conv. OFDM system over fading channel

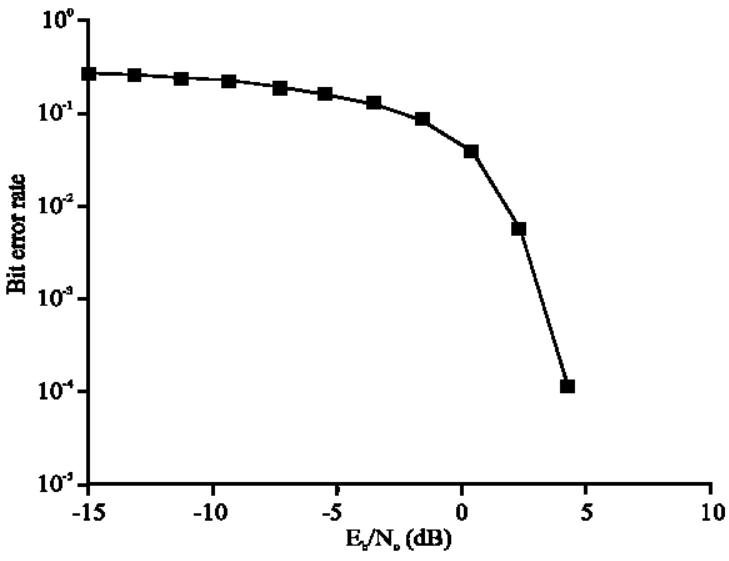

Fig. 9: BER vs. $E_{b} / N_{0}$ performance when using the proposed OFDM system over AWGN channel

by increasing the BER. So that, BER vs. $E_{b} / N_{0}$ performance of conventional OFDM system over AWGN and fading channels are shown in Fig. 7 and 8, respectively. While, the BER vs. $E_{b} / N_{0}$ performance when using the proposed OFDM system over AWGN and fading channels are shown in Fig. 9 and 10, respectively.

Finally, it is shown from Fig. 10 that BER vs. $\mathrm{E}_{b} / \mathrm{N}_{0}$ performance is improved extremely over AWGN and fading channels when using the proposed OFDM system. So that BER is approximately $10^{-4}$ at $\mathrm{E}_{\mathrm{b}} / \mathrm{N}_{0}=4 \mathrm{~dB}$ over AWGN when using the proposed system. While, BER is approximately $10^{-1.89}$ at $\mathrm{E}_{\mathrm{b}} / \mathrm{N}_{0}=4 \mathrm{~dB}$ over AWGN when using the conventional system. In fading channel, the smallest BER value approximately is $10^{-3.8921}$ is obtained at $E_{b} / N_{0}=26 \mathrm{~dB}$ when using the proposed system. While, the smallest BER value equals to $10^{-3.199}$ at $\mathrm{E} / \mathrm{N}$ is approximately $26 \mathrm{~dB}$ when using the conventional system.

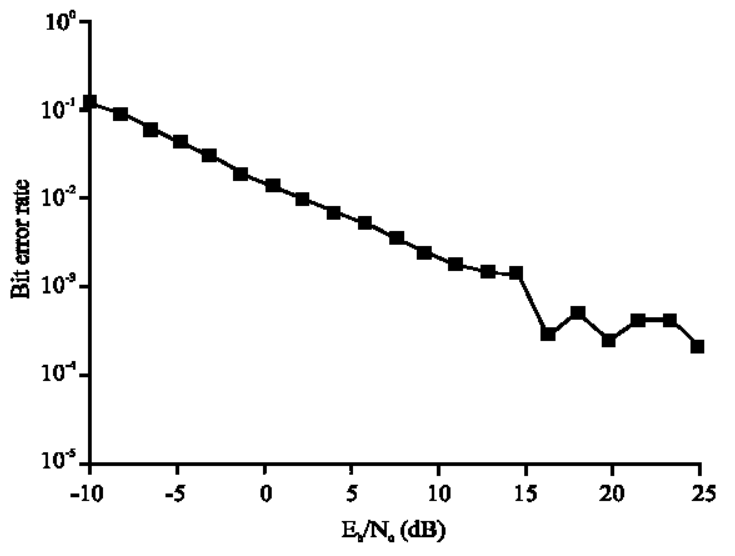

Fig. 10: BER vs. $E_{b} / N_{0}$ performance when using the proposed OFDM system over fading channel

\section{CONCLUSION}

Performance of OFDM system is degraded due to Large PAPR value, this problem makes high power amplifier operate in nonlinear region which distorting the signal. Thus, BER will be increased and consuming extra power by amplifier. Many previous researches had studied PAPR reduction. But most of them have either poor BER performance or computational and hardware complexity. In this research, it proposed OFDM system based on $\mathrm{BCH}$ channel coding and DCT technique to enhance OFDM system performance. Here, $\mathrm{BCH}$ is used for both detecting and correcting errors as well as to reduce PAPR because of the redundant bits. While, DCT in the proposed system is used to extremely reduce the PAPR. From results, it is shown that acceptable PAPR value is obtained, so that, PAPR is approximately 4.233 $\mathrm{dB}$. PAPR when using the proposed system is reduced by $0.707 \mathrm{~dB}$ in compared with using DCT only while it is reduced by $11.767 \mathrm{~dB}$ in compared with the conventional system. This reduction in PAPR guarantee leads to reduce BER because HPA will not produce any distortion. BER also is improved over AWGN and fading channels when using the proposed OFDM system because of using $\mathrm{BCH}$ channel coding which correct four errors in each OFDM signal. So that, the BER value equals to $10^{-4}$ at $\mathrm{E}_{\mathrm{b}} / \mathrm{N}_{0}=4 \mathrm{~dB}$ over AWGN channel while smallest BER value equals to $10^{-3.8921}$ at $\mathrm{E}_{\mathrm{b}} / \mathrm{N}_{0}=26 \mathrm{~dB}$ is obtained over fading channel. Finally, the proposed OFDM system performance is better than conventional OFDM system. In comparing with the exist study in method (Mhatre and Khot, 2015; Muralibabu et al., 2012), the reduction of PAPR in this study is better. So that, heavily reduction in PAPR value is obtained without serious increasing in computational complexity, low cost and simple hardware implementation. 


\section{ACKNOWLEDGEMENT}

This research was supported by the Islamic University research grant PRG-IUNAJAF-2019.

\section{REFERENCES}

Albdran, S., A. Alshammari and M. Matin, 2012. Clipping and filtering technique for reducing PAPR in OFDM. IOSR J. Eng., 2: 91-97.

Alekya, B.H.B. and O.C. Mohana, 2016. Combined DCT and companding for PAPR reduction in OFDM signals. Intl. J. Innovative Res. Sci. Technol., 2: 730-735.

Chih-Peng, L., W. Sen-Hung and W. Chin-Liang, 2010. Novel low-complexity SLM schemes for PAPR reduction in OFDM systems. IEEE. Trans. Signal Process., 58: 2916-2921.

Cho, Y.S., J. Kim, W.Y. Yang and C.G. Kang, 2010. MIMO-OFDM Wireless Communications with MATLAB. John Wiley \& Sons, Hoboken, New Jersey, USA., ISBN:978-0-470-82561-7, Pages: 544.

Choudhary, C. and V. Gupta, 2013. A study of performance enhancement schemes for multicarrier transmission. Intl. J. Comput. Appl., 68: 50-54.

Edfors, O., M. Sandell, J.J.V.D. Beek, S.K. Wilson and P.O. Borjesson, 1995. Analysis of DFT based channel estimators for OFDM. Proceedings of the 1995 Conference on Vehicular Technology (VTC'95), July 25-28, 1995, Lulea University of Technology, Lulea, Sweden, pp: 815-819.

Garg, S., A.K. Sharma and A.K. Tyagi, 2017. Performance analysis of $1 / 2$ code rate convolution encoded DWTOFDM system with different modulation schemes. Intl. J. Innovative Res. Sci. Eng., 3: 109-119.

Gupta, N. and D.K. Saxena, 2013. Implementation and contrasting comparision of transform techniques of OFDM. Intl. J. Comput. Appl., 72: 47-51.

Gupta, S. and S.S. Bhadauria, 2013. Comparison of bit error rate in OFDM system by using MMSE equalizer. IMPACT. Intl. J. Res. Eng. Technol., 1: 25-34.

Hsu, C.Y. and H.G. Do, 2007. The new peak-to-average power reduction algorithm in the OFDM system. Wireless Pers. Commun., 41: 517-525.

Jagadeesh, D., 2007. Simulation of wireless communication system using OFDM principle. Ph.D Thesis, National Institute of Technology, Rourkela, India.

Jayashri, R., S. Sujatha and P. Dananjayan, 2015. DCT based partial transmit sequence technique for PAPR reduction in OFDM transmission. ARPN. J. Eng. Appl. Sci., 10: 2182-2186.
Joshi, H.D., 2012. Performance augmentation of OFDM system. Ph.D Thesis, Jaypee University of Engineering and Technology, Raghogarh-Vijaypur, India.

Khalid, S., 2009. Peak to average power ratio reduction in orthogonal frequency division multiplexing system. Ph.D Thesis, University of Engineering and Technology, Taxila, Pakistan.

Koudougnon, H., I. Chana and M. Belkasmi, 2012. Combined coding and companding to reduce both PAPR and BER in OFDM systems. Intl. J. Comput. Sci. Issues, 9: 195-201.

Mhatre, K. and U.P. Khot, 2015. Efficient selective mapping PAPR reduction technique. Procedia Comput. Sci., 45: 620-627.

Minallah, M.S. and G. Raja, 2006. Real time FFT processor implementation. Proceedings of the International Conference on Emerging Technologies (ICET'06), November 13-14, 2006, IEEE, Peshawar, Pakistan, ISBN:1-4244-0502-5, pp: 192-195.

Muralibabu, K., K.R. Naidu, S. Padmanabhan and G.P. Kumar, 2012. PAPR reduction using combined LDPC and DCT with companding trans form in OFDM system. Intl. J. Eng. Res. Dev., 3: 33-38.

Natalia, R. and R. Mathar, 2008. PAPR reduction in OFDM systems. Master's Thesis, Polytechnic University of Catalonia, Barcelona, Spain.

Patidar, L. and A. Parikh, 2011. BER comparison of DCT-based OFDM and FFT-based OFDM using BPSK modulation over AWGN and multipath Rayleigh fading channel. Int. J. Comput. Applic., 31: 38-41.

Pischella, M. and D.L. Ruyet, 2015. Digital Communications 2Digital Modulations. John Wiley \& Sons, New York, USA., ISBN:978-1-84821-846-8, Pages: 299.

Pradeep, K.G., S. Garima andK.S. Pankaj, 2013. Reduction of PAPR value using combined RS coding and i-Law companding in OFDM system. Intl. J. Eng. Res. Technol., 2: 2921-2924.

Ryan, W.E. and S. Lin, 2009. Channel Codes: Classical and Modern. Cambridge University Press, Cambridge, England, UK., ISBN:978-0-521-84868-8, Pages: 691.

Sajedin, M., A. Ghorbani and H.R.A. Davar, 2014. Nonlinearity compensation for high power amplifiers based on look-up table method for OFDM transmitters. Intl. J. Adv. Comput. Sci. Inf. Technol., 3: 354-367.

Sklar, B., 2001. Digital Communications: Fundamentals and Applications. 2nd Edn., Prentice-Hall, Upper Saddle River, New Jersey, USA., pp: 1079.

Viswanathan, M., 2013. Simulation of Digital Communication Systems using Matlab. 2nd Edn., Amazon Publishing, Seattle, Washington, USA., Pages: 258. 